\title{
POLÍTICA E SECULARIZAÇÃO EM CARL SCHMITT
}

\author{
Helton Adverse* \\ heltonadverse@hotmail.com
}

Nada há de sacro que seja puramente espiritual.

(Hofmannstahl)

RESUMO $O$ artigo visa examinar alguns aspectos da relação entre política e secularização em Carl Schmitt, partindo de sua análise da subjetividade romântica em Romantismo Político.

Palavras-chave Romantismo político; Secularização; Metafísica; Carl Schmitt.

ABSTRACT The article's aim is to examine some aspects of the relation between politics and secularization in the thought of Carl Schmitt, departing of his analysis of the romantic subjectivity in his book Political Romanticism.

Keywords Political romanticism; Secularization; Metaphysics; Carl Schmitt.

"Existem hoje muitos modos de se posicionar metafisicamente em forma secularizada." ${ }^{1}$ Ao ler essa frase de Schmitt somos levados a acreditar

* Professor do Departamento de Filosofia da UFMG. Artigo recebido em junho de 2008 e aprovado em novembro de 2008.

1 "Viele Arten metaphysicher Haltung existieren heute in säkularisierter Gestalt". C. Schmitt, Politische Romantik [1919]. Berlim: Duncker \& Humblot, 1998 (6 edição), p. 18.

KRITERION, Belo Horizonte, nº 118, Dez./2008, p. 367-377. 
que a metafísica é um destino e que qualquer esforço por se livrar de suas categorias não apenas é vão mas parece reforçá-las. O "velho Deus morto", como dizia Nietzsche, talvez tenha nos pregado uma bela peça: deixou sua pobre criatura vagar livremente para mostrar que o caminho já estava traçado: In Arcadia Ego. Para colocar o problema em termos mais precisos, está em jogo aqui a "secularização", isto é, o processo, intensificado na modernidade, no qual categorias teológico-metafísicas migraram de sua esfera original (o transcendente) para serem aplicadas na esfera mundana.

Originalmente, o termo "secularização", lembra G. Marramao, é uma metáfora surgida na época da Reforma em âmbito jurídico, indicando "a expropriação de bens eclesiásticos em favor dos príncipes ou das igrejas nacionais reformadas". Mais tarde, ao longo do século XIX, o termo sofreu "uma notável extensão semântica"; primeiro, "no campo histórico-político, em seguida à expropriação dos bens e dos domínios religiosos fixada pelo decreto napoleônico de 1803 e posteriormente no campo ético e sociológico quando assume o significado de categoria genealógica capaz de conter em si o sentido unitário da evolução histórica da sociedade ocidental moderna."” No entanto, o sentido que gostaria de reter não é propriamente histórico nem sociológico, mas, digamos (na ausência de um termo melhor), filosófico. Poderia então ressaltar que nessa passagem das categorias de um registro a outro é retirado o que há de propriamente teológico (seus conteúdos) e retido seu aspecto formal. Além do mais, se dirigirmos nossa atenção para Schmitt, veremos que a secularização não se reduz aos aspectos epistêmico e prático porque concerne a uma atitude, a uma postura (Haltung). O texto de Schmitt nos ajuda a entender melhor a questão:

Em grande medida, o lugar de Deus para o homem moderno foi ocupado por outros fatores, por certo mundanos [terrenos, irdische], como a humanidade, a nação, o indivíduo, o desenvolvimento histórico ou também a vida como vida por si mesma, em sua total banalidade (Geistlosigkeit) e mero movimento. A postura não deixa de ser metafísica por isso. O pensamento e o sentimento de cada homem contêm sempre um determinado caráter metafísico. A metafísica é algo inevitável e, como Otto von Gierke observou corretamente, não se pode escapar a ela renunciando a dela tomar consciência. A isso chamo de secularização. ${ }^{3}$

Está fora do alcance de minhas capacidades, e dos objetivos deste pequeno artigo, colocar em exame a tese da secularização. $O$ que me

2 G. Marramao, Poder e secularização. As categorias do tempo. Trad. de G. A. Gomez de Andrade. São Paulo: Editora Unesp, 1995, p. 29. Ver também do mesmo autor Céu e terra. Genealogia da secularização. Trad. de G. A. Gomez de Andrade. São Paulo: Editora Unesp, 1994. lbidem. 
interessa, em primeiro lugar, é analisar algumas de suas conseqüências no âmbito do pensamento político. Gostaria, então, de investigar as implicações filosóficas da adoção da tese da secularização ou, dizendo de outra maneira, que espécie de filosofia política ela informa. Mas não somente isso. Proponho também fazer um "recuo" com relação à tese para tentar compreender a que necessidade ela atende. Sem problematizar a tese ela mesma, a tomarei em suas duas "extremidades", vale dizer, seus efeitos e sua origem. A primeira exigência, contudo, é apresentar de maneira um pouco mais rigorosa a tese da secularização tal como a encontramos na obra de Schmitt. Para tanto, vou tomar como ponto de partida as análises presentes em Romantismo político.

\section{I}

Como transparece na passagem citada acima, a noção de secularização em Schmitt está associada à idéia de substituição, ou melhor, de transferência ou transposição. Trata-se da transposição de conceitos religiosos ou teológicos para a esfera mundana/política. A esse respeito, o texto de Schmitt mais eloqüente é Teologia política I. Com efeito, encontramos no terceiro capítulo seguinte afirmação:

Todos os conceitos significativos da teoria do Estado moderna são conceitos teológicos secularizados. Não somente de acordo com seu desenvolvimento histórico, porque ele foi transferido da teologia para a teoria do Estado, à medida que o Deus onipotente tornou-se o legislador onipotente, mas, também, na sua estrutura sistemática, cujo conhecimento é necessário para uma análise sociológica desses conceitos. ${ }^{4}$

Mas Teologia política I, embora chame a atenção para a analogia estrutural entre os conceitos teológicos e os conceitos políticos, não nos esclarece a respeito da origem histórica da secularização, o que Schmitt realiza no livro de 1919. Isso se explica da seguinte maneira: a secularização é um fenômeno concernente à modernidade e se quisermos remontar a suas origens precisamos ter em mente como Schmitt entende o começo da modernidade.

No segundo capítulo de Romantismo político Schmitt escreve que "no começo da modernidade se encontram duas grandes transformações que podem associar-se em um interessante contramovimento". Em primeiro lugar, "com o sistema planetário copernicano, a cujo significado transformador

4 C. Schmitt, Teologia política. Trad. de E. Antoniuk. Belo Horizonte: Del Rey, 2006, p. 35 (trad. modificada). Utilizo também como referência a tradução francesa Théologie politique. 1922-1969. Trad. de J. L. Schlegel. Paris: Gallimard, 1988, p. 46. 
remeteu-se Kant de boa vontade, a Terra deixou de ser o ponto central do universo". Em seguida, "com a filosofia de Descartes começou-se a abalar o antigo pensamento ontológico; sua argumentação cogito, ergo sum remeteu o homens a um fato subjetivo interno, a seu pensamento, em lugar de a uma realidade do mundo exterior." 5 Dessa maneira, o pensamento científiconatural deixou de ser geocêntrico para buscar seu fundamento fora da Terra, ao passo que o pensamento filosófico tornou-se "egocêntrico", isto é, "buscou seu centro em si mesmo." Como conseqüência, a filosofia moderna, desde seu nascimento, ficou marcada por uma tensão interna, uma espécie de cisão ou de dilema (Zwiespalt) entre o pensamento e o ser, o conceito e a realidade, o espírito e a natureza, o sujeito e o objeto. ${ }^{7}$ Isso quer dizer que o centramento do sujeito em si mesmo, proposto pela filosofia cartesiana, teve como resultado um esvaziamento da realidade do mundo externo: "a própria ordem do mundo se torna um problema e, em última instância, pode ser vista como algo irracional ou inexplicável." ${ }^{\text {R }}$ Resultou dessa cisão a tentativa de superação dessas oposições, com o claro objetivo de restituir ao sujeito pensante, ao espírito, a inteligibilidade do mundo empírico. Mas já em Kant esse empreendimento está destinado a fracassar, pois que a essência da realidade empírica, a coisa em si, não pode ser apreendida. A filosofia pós-kantiana tomou por tarefa superar a inexplicabilidade e a irracionalidade do ser real, seja pela afirmação de um eu absoluto que põe a si mesmo e a seu contrário (o mundo, o não-eu) em Fichte, seja na crítica que Schelling faz a este último impedindo de tomar o absoluto como subjetivo ou como objetivo, mas localizando-o "em um ponto de indiferença entre ambos". Para Schmitt, a referência ao idealismo pós-kantiano atende a dois interesses: o primeiro é mostrar a impossibilidade de atender às aspirações do romantismo com essa espécie de crítica do racionalismo dos séculos XVII e XVIII. Fichte e Schelling, e mesmo Hegel, não incluem em seus sistemas um tratamento emotivo dos problemas filosóficos, o que torna suas filosofias pouco atraentes para os que adotam a postura romântica. O segundo interesse, porém (e o que me parece mais importante destacar) é que vamos reconhecer no idealismo pós-kantiano a presença de Spinoza. Na verdade, o spinozismo, como filosofia da imanência, está no cerne da reação filosófica ao racionalismo:

5 C. Schmitt, Politische Romantik, op. cit., p. 62.

6 C. Schmitt, Politische Romantik, op. cit., p. 62.

7 Ibidem, p. 63.

8 B. Ferreira, O risco do político. Crítica ao liberalismo e teoria política no pensamento de Carl Schmitt. Belo Horizonte: Editora UFMG, 2004, p. 83.

9 C. Schmitt, Politische Romantik, op. cit., p. 63. 
Mas o sistema de Spinoza é a primeira reação, e na verdade análoga àquela outra pós-kantiana, contra a abstração do racionalismo moderno, representado então por Descartes e Hobbes, e contra uma concepção mecânica do mundo. A cisão característica - que se distingue claramente não apenas em Descartes, mas também de forma especialmente interessante em Hobbes - entre um fenomenalismo que considera o mundo exterior como mera percepção e um materialismo caracterizado do mesmo modo, isto é, que somente reconhece movimentos dos corpos, é superada; pensamento e ser se convertem em atributos da mesma substância infinita. ${ }^{10}$

Além dessa “aspiração filosófica” para se chegar à realidade inapreensível para o racionalismo abstrato, Schmitt destaca três formas de oposição à desconstrução do antigo pensamento ontológico: a místico-religiosa; a históricotradicionalista; a emotivo-esteticista, alojando nesta última a reação romântica. Essas formas não são puras, sendo possível, por exemplo, detectar elementos místicos na reação filosófica, como facilmente se percebe no próprio Spinoza. Mas o que Schmitt termina por mostrar em seu texto é que essas reações apenas podem ser devidamente compreendidas se reconstituímos o fundo metafísico no qual elas se formam. Assim, a emergência do Romantismo somente foi possível a partir de uma mudança "que tem lugar porque o desenvolvimento metafísico do século XVII ao XIX conduz a novas representações de Deus e do absoluto." ${ }^{11}$ Em que consiste essa mudança?

A realidade mais alta e mais segura da antiga metafísica, o Deus transcendente, foi eliminada. Mais importante que a disputa dos filósofos foi a pergunta acerca de quem assumia suas funções como realidade mais alta e mais segura e, desse modo, como instância última de legitimação da realidade histórica. Apareceram duas novas realidades seculares que impuseram uma nova ontologia, sem esperar a finalização da discussão epistemológica: a humanidade e a história. Completamente irracionais, se são consideradas com a lógica da filosofia racionalista do século XVIII, mas objetivas e evidentes em sua validade supra-individual, dominam in realitate o pensamento da humanidade como os dois novos demiurgos. ${ }^{12}$

Tomando-o sob esse aspecto, o fenômeno da secularização tem como contrapartida, na esfera política, a sacralização do político, como vemos em Rousseau. Segundo Schmitt, no Contrato social a "política se torna uma questão religiosa"13, o que permite estabelecer uma relação de continuidade entre sua obra filosófica e o jacobinismo. Vou me permitir negligenciar os detalhes da análise de Schmitt porque eles concernem propriamente ao tema

10 Ibidem, p. 64.

11 C. Schmitt, Politische Romantik, op. cit., p. 68.

12 Ibidem.

13 Ibidem, p. 69. 
do Romantismo. Apenas faço observar que essas novas idéias de sociedade (humanidade) e história desempenharão um papel muito importante na produção da subjetividade romântica. Mais precisamente, o que o sujeito romântico busca extrair de si mesmo (a fusão entre o finito e o infinito, entre o discursivo e o intuitivo, a superação das oposições e dos conflitos) somente poderia ser alcançado sob a condição de que contemple a humanidade e a história. A esses dois novos demiurgos é assinalada essa tarefa de unificação. ${ }^{14}$ Desnecessário dizer que essa pretensão, no romantismo, inevitavelmente fracassa, pois se transforma em um "esteticismo" no qual o mundo, esvaziado de seu sentido próprio, será a ocasião para a manifestação da subjetividade; o mundo resume-se a um objeto da experiência individual. Mas deixo de lado as especificidades do ocasionalismo romântico para me deter sobre o problema do suporte metafísico que o sustenta.

Claro está que, para Schmitt, o romantismo, ao levar a cabo a emancipação do sujeito, termina por compartilhar os mesmos pressupostos metafísicos da filosofia cartesiana e, portanto, aprofunda as aporias do pensamento moderno em lugar de solucioná-las. ${ }^{15}$ A partir daí, gostaria de fazer duas considerações: a primeira é a de que a noção de secularização veicula uma crítica à modernidade na qual a emancipação do sujeito tem como contrapartida a desestabilização da ordem externa das coisas. As reações que essa desestabilização suscita não são capazes, contudo, de restituir a unidade da experiência. Por isso, a filosofia moderna está condenada a uma interminável recherche de la réalité. A segunda consideração é a seguinte: se a metafísica imanentista pôde operar uma sacralização do político foi porque operou por substituição, assim como no caso do ocasionalismo romântico houve uma substituição de Deus pelo sujeito. Não resta dúvida de que um dos objetivos de Schmitt ao escrever o Romantismo político é mostrar como a secularização do Deus transcendente como eu romântico corresponde a um "endeusamento do indivíduo liberal, do produtor-consumidor no livre mercado." liberalismo a relação é de duplo pertencimento, não é difícil concluir que o sujeito liberal estará tão disposto a se esquivar da tomada de decisão política quanto o sujeito romântico se evade da realidade e migra para a esfera da fruição estética. Mas como minha intenção é tentar compreender o sentido da noção de secularização, acredito que vale a pena notar que na crítica de

14 Ibidem, p. 78.

15 A respeito, ver B. Ferreira, O risco do político, op. cit., pp. 86-7, mas também C. Galli, Genelogia della política. Bolonha: II Mulino, 1996, pp. 195-228 e o artigo de R. P. Canosa presente neste mesmo volume.

16 J. Dotti, apresentação à tradução espanhola de Politische Romantik. C. Schmitt, Romantismo político. Trad. de L. Rossi e S. Schwarzböck. Universidad Nacional de Quilmes, p. 20. 
Schmitt à desconstrução da "antiga ontologia" está presente a denúncia do uso que é feito de determinadas idéias, as quais, em contrapartida, não são criticadas elas mesmas. A idéia religiosa ou mística de paraíso perdido, por exemplo, é utilizada pelos românticos tendo em vista uma finalidade distinta de sua formulação original. Espero deixar isso mais bem explicado se me referir ao problema da analogia estrutural entre o teológico e o político em Schmitt.

Tal como aparece em Romantismo político, a noção de secularização desempenha uma função crítica. Podemos detectar aí um procedimento semelhante àquele que Karl Löwith irá adotar trinta anos depois em Meaning in history. Sua tese célebre é a de que a moderna noção de progresso consiste em uma versão secularizada da escatologia judaico-cristã. ${ }^{17}$ Em Schmitt essa crítica opera sobre um pano de fundo, a saber, a impossibilidade de a modernidade conferir forma (Form) à realidade. Voltemos ao prólogo de Romantismo politico:

Atualmente, a dissolução da cultura e das formas tradicionais continuou aprofundandose, mas a nova sociedade não encontrou ainda sua forma própria. Também ela não criou uma nova arte e se move dentro da discussão artística iniciada pelo romantismo, renovada a cada nova geração que vai se formando e com a romantização mutável de formas alheias. ${ }^{18}$

Essa tese, de caráter geral, segundo a qual a sociedade moderna ainda não encontrou sua forma, é mais bem compreendida se vista à luz das hipóteses que Schmitt avança em Catolicismo romano e forma política. Um dos pontos centrais de sua argumentação é a vinculação entre forma e representação. Uma sociedade que estabelece o fundamento da vida coletiva na esfera da produção, isto é, no econômico, é incapaz de representação e, concomitantemente, incapaz de forma. É característico do pensamento econômico renunciar a qualquer espécie de representação ${ }^{19}$. Intimamente vinculado à precisão técnica, permanece alheio a toda idéia representativa: "O econômico, em sua conexão com o técnico, pretende uma presença real das coisas." ${ }^{20}$ Esse não é o único

17 K. Löwith, Meaning in history. Chicago: The University of Chicago Press, 1949. Vale lembrar a crítica que Löwith fará à interpretação schmittiana do romantismo. Segundo Löwith, ao partilhar dos mesmos pressupostos, o decisionismo de Schmitt seria uma forma de ocasionalismo. Ver "The Occasional Decisionism of Carl Schmitt”. In: Martin Heidegger and European Nihilism. Nova York: Columbia University Press, 1998, pp. 137-69. Para uma discussão sobre a leitura de Löwith, ver C Galli, Genealogia della política, op. cit., pp. 212-8.

18 C. Schmitt, Politische Romantik, op. cit., p. 15.

19 C. Schmitt, Catolicismo y forma política. Trad. de C. R. Miguel. Madri: Tecnos, 2000, p. 25.

20 Ibidem. 
motivo pelo qual o pensamento econômico não pode ser representativo. Ainda é preciso lembrar o fato de que a sociedade burguesa inviabiliza a noção de representatividade pois os tipos que a povoam (o intelectual, o comerciante) são somente servidores da "grande máquina" da vida econômica. Em suma, não é possível representar o consumo ou a produção. ${ }^{21}$

A secularização, portanto, parece evidenciar a incapacidade da sociedade moderna conferir um fundamento para a ordem, ou ainda de construir uma ordem política. Dizendo de outra maneira, a secularização aparece como o pis aller de uma sociedade que perdeu de vista o transcendente, mas não inteiramente. As categorias metafísicas restam, assim como resta a única instituição capaz de conferir forma jurídica, estética e política na atualidade: a Igreja Católica. Seu poder representativo é evidenciado pelo fato de seu líder supremo ser o vigário da figura ausente do cristo. A Igreja mantém viva assim a noção de autoridade sob a qual pode se abrigar uma autêntica prática política. A tentativa de substituir a representação do transcendente pela idéia de humanidade se revela infrutífera, pois esta é por demais abstrata, assim como fracassa a iniciativa liberal de fundar a prática política de governar sobre leis imanentes: "nem as coisas nem as pessoas necessitam de um 'governo' quando o mecanismo do econômico e do técnico cede a leis imanentes." 22

Mas tenho a impressão de que há ainda um outro aspecto da secularização que merece consideração. Avançando em direção ao segundo tópico desta investigação - isto é, o concernente às conseqüências da adoção da tese da secularização -, quero tomar o problema por um outro viés, o da teologia política. A secularização vai aparecer aqui como reveladora dos laços entre teologia e metafísica, "fatores estruturantes da vida política." 23

\section{II}

Já me referi à analogia estrutural entre o teológico e o político em Schmitt. Quero agora problematizar o tema fazendo referência à sua crítica à modernidade. $\mathrm{O}$ ponto de partida será a crítica que $\mathrm{H}$. Blumenberg dirige a Schmitt em The legitimacy of modern age:

O que é notável, metodologicamente, na "teologia política" de Carl Schmitt é que ela não encontra qualquer valor neste nexo de secularização desde que (como me parece) teria sido mais natural, em vista da intenção desta "teologia política", estabelecer 
a relação de derivação inversa interpretando a aparente derivação teológica dos conceitos políticos como uma conseqüência da qualidade absoluta das realidades políticas. $^{24}$

Não vou reproduzir aqui o teor da discussão com Schmitt, que sentiu necessidade de responder às críticas de Blumenberg em Teologia política II. A hipótese que gostaria de avançar é a de que talvez Schmitt tenha conferido mais valor ao nexo que a secularização estabelece entre o teológico e as teorias modernas do Estado do que Blumenberg parece reconhecer.

Schmitt situa sua análise desse conceito no quadro de uma "sociologia dos conceitos jurídicos" 25 , isto é, está em questão o estabelecimento de relações entre os conceitos jurídicos e o contexto sócio-cultural em que eles aparecem (as concepções teológicas e filosóficas. Vale lembrar ainda que Teologia política I compunha uma série de textos em homenagem a Max Weber). O método que Schmitt adota então consiste na apresentação das analogias presentes em diversos textos jurídicos entre a teologia, o direito e a política. Mais uma vez sai reforçada a tese da correspondência entre as concepções metafísicas e políticas. Sendo assim, a sociologia do conceito jurídico de soberania é a constatação da identidade entre a "imagem metafísica que uma certa época faz do mundo" e a "estrutura do que lhe parece a forma de sua organização política." ${ }^{26}$ Contudo, o que chama a atenção nesse texto é a nova apreciação que Schmitt faz da filosofia moderna, em geral, e de Descartes, em particular. Com efeito, o pensamento cartesiano não é mais o destruidor da velha ontologia e sim o representante de uma metafísica em que a teologia e a política convergem na afirmação da existência de um soberano legislador, o Deus supremo fundamento último do existente e o Monarca Absoluto: " $C$ 'est Dieu qui a établi ces lois en nature ainsi qu'un roi a établi les lois em son royaume", diz Descartes em uma carta a Mersenne. ${ }^{27}$ Por isso Schmitt pode concluir:

Os séculos XVII e XVIII eram dominados por essa idéia; excluindo a forma decisionista de seu pensamento, um dos motivos pelos quais Hobbes, apesar do nominalismo e cientificidade das ciências naturais, apesar de sua redução do indivíduo ao átomo, permanece personalista e postula uma última instância concreta decisiva e também eleva seu Estado, o Leviathan, a uma pessoa monstruosa, justamente no sentido mitológico. Nele, isso não é antropomorfismo; disso ele estava inteiramente

$24 \mathrm{H}$. Blumenberg, The legitimacy of the modern age. Trad. de R. M. Wallace. Cambridge: The MIT Press, 1995, p. 92.

25 C. Schmitt, Teologia política, op. cit., p. 36.

26 C. Schmitt, Teologia política, op. cit., p. 43.

27 Ibidem, p. 44. 
livre. Trata-se de uma necessidade metódica e sistemática de um pensamento jurídico. A imagem do arquiteto e construtor do mundo contém, entretanto, a falta de clareza do conceito de causalidade. O construtor do mundo é, simultaneamente, autor e legislador, ou seja, autoridade legitimadora. Durante todo o Iluminismo e a Revolução Francesa, aquele que constrói o Estado e o mundo é o législateur. ${ }^{28}$

Essa concepção teísta (decisionista) permanece viva na política, segundo Schmitt, até o século XIX, quando é substituída por uma concepção deísta em que Deus, embora ainda artífice da grande máquina do universo, dele é repelido uma vez que ela funciona automaticamente. Ou ainda, a concepção de lei como emanação da vontade de Deus cede lugar a uma concepção científica em que a validade do princípio jurídico é "identificada com a lei de natureza vigente sem exceção." 29 Nesta nova concepção não há mais lugar para o milagre assim como na esfera jurídica não há mais lugar para a exceção. A modernidade aparece aqui cindida em duas metafísicas; logo, em duas teologias políticas. A primeira seria expressa nas ideologias de inclinação/ tendência liberal e informa uma compreensão da realidade em que predomina a idéia de imanência: "No século XIX, tudo é sempre dominado, com cada vez mais expansão, por idéias de imanência. Todas as identidades, que retornam na doutrina política e jurídico-estatal do século XIX, baseiam-se em tais idéias de imanência" ${ }^{30}$. A outra reteria a noção de transcendência e seria de caráter decisionista, manifestando-se inicialmente no século XVII (e encontrando sua formulação mais precisa em Hobbes) e mais tarde no pensamento contrarevolucionário, especialmente em Donoso Cortés.

Nessa nova abordagem da metafísica moderna não seria possível encontrar a possibilidade de um outra consideração, mais positiva, da secularização? Se o princípio decisionista não é incompatível com a metafísica moderna, então a secularização, que ela inegavelmente operou, guarda ainda um interesse político. Se isso for verdade, então a crítica de Schmitt à modernidade tem de ser avaliada a partir de sua leitura dos autores modernos que, em um contexto de secularização, conceberam a política em termos personalistas ${ }^{31}$. Nesse caso, a secularização assumiria um outro papel na teoria de Schmitt: reivindicando a conexão entre teologia e política, oferece a única possibilidade de uma

\footnotetext{
28 Ibidem.

29 Ibidem.

30 Ibidem, p. 46.

31 Isso significaria também acentuar a distinção entre Schmitt e os românticos sem necessitar referir, como faz C. Galli, à partilha de uma mesma metafísica em que o mundo é tomado como "jogo" e o real tomado em sua indeterminação (ver C. Galli, Genealogia della política, op. cit., p. 216).
} 
fundamentação para o político em um tempo no qual a perda da transcendência implica constantemente a ameaça de "esvaziamento do mundo".

\section{Referências}

BLUMENBERG, H. The legitimacy of the modern age. Trad. de R. M. Wallace. Cambridge: The MIT Press, 1995.

FERREIRA, B. O risco do político. Crítica ao liberalismo e teoria política no pensamento de Carl Schmitt. Belo Horizonte: Editora UFMG, 2004.

GALLI, C. Genealogia della política. Carl Schmitt e la crisi del pensiero político moderno. Bolonha: Il Mulino, 1996.

LÖWITH, K. Meaning in history. Chicago: The University of Chicago Press, 1949.

- Martin Heidegger and European Nihilism. Nova York: Columbia University Press, 1998.

MARRAMAO, G. Poder e secularização. As categorias do tempo. Trad. de G. A. Gomez de Andrade. São Paulo: Editora Unesp, 1995.

- Céu e terra. Genealogia da secularização. Trad. de G. A. Gomez de Andrade. São Paulo: Editora Unesp, 1994.

SCHMITT, C. Politische Romantik [1919]. Berlim: Duncker \& Humblot, 1998 (6 edição).

Teologia política. Trad. de E. Antoniuk. Belo Horizonte: Del Rey, 2006.

Théologie politique. 1922-1969. Trad. de J. L. Schlegel. Paris: Gallimard, 1988.

Catolicismo y forma política. Trad. de C. R. Miguel. Madri: Tecnos, 2000. 